\title{
Review
}

\section{Cyclin-dependent kinase-1: linking apoptosis to cell cycle and mitotic catastrophe}

\author{
M Castedo ${ }^{1}$, J-L Perfettini ${ }^{1}$, T Roumier ${ }^{2}$ and G Kroemer $^{\star}, 1$ \\ 1 Centre National de la Recherche Scientifique, UMR1599, Institut Gustave \\ Roussy, 39 rue Camille-Desmoulins, F-94805 Villejuif, France; \\ * Corresponding author: Tel: 33-1-42 1160 46; Fax: 33-1-42 1160 47; \\ E-mail:kroemer@igr.fr
}

Received 1.8.02; accepted 9.8.02

Edited by G Melino

\begin{abstract}
The cyclin-dependent kinase 1 (Cdk1), formerly called Cdc2 (or p34 ${ }^{\text {Cdc2 }}$ ), interacts with cyclin B1 to form an active heterodimer. The activity of Cdk1 is subjected to a complex spatiotemporary regulation, required to guarantee its scheduled contribution to the mitotic prophase and metaphase. Moreover, the activation of Cdk1 may be required for apoptosis induction in some particular pathways of cell killing. This applies to several clinically important settings, for instance to paclitaxel-induced killing of breast cancer cells, in which the ErbB2 receptor kinase can mediate apoptosis inhibition through inactivation of Cdk1. The activation of Cdk1 participates also in HIV-1-induced apoptosis, upstream of the p53-dependent mitochondrial permeabilization step. An unscheduled Cdk1 activation may contribute to neuronal apoptosis occurring in neurodegenerative diseases. Finally, the premature activation of Cdk1 can lead to mitotic catastrophe, for instance after irradiation-induced DNA damage. Thus, a cell type-specific modulation of Cdk1 might be taken advantage of for the therapeutic correction of pathogenic imbalances in apoptosis control.

Cell Death and Differentiation (2002) 9, 1287 - 1293. doi:10.1038/ sj.cdd. 4401130
\end{abstract}

Keywords: apoptosis; caspases; cell death

Abbreviations: AIF, apoptosis inducing factor; FAD, flavine adenine dinucleotide; NAD, nicotine amide dinucleotide

The cyclin-dependent kinase 1 (Cdk1), formerly called Cdc2 (or p34 ${ }^{\mathrm{Cdc2}}$ ), interacts with cyclin B1 to form an active heterodimer, the 'mitosis-promoting factor' whose activity determines the cell cycle timing of mitosis. In addition, Cdk1 activation has initially been suggested to be a stringent requirement for the entry into apoptosis. ${ }^{1}$ However, several studies have shown that apoptosis can occur in postmitotic neurons in the absence of detectable Cdk1 expression, ${ }^{2}$ and in both serum-deprived fibroblasts and immature thymocytes, apoptosis can proceed without activation of the low level of Cdk1 found in these cells., ${ }^{3,4}$ Although, this eliminates the possibility that Cdk1 would be part of the central executioner of apoptosis, recent data indicate that Cdk1 does play an important role in some particular lethal signal transduction pathways, as will be discussed in this review.

\section{Regulation of the cyclin B/Cdk1 complex during mitosis}

Progression from G2- to M-phase is driven by activation of the Cdk1/cyclin B1 complex, whose activity must be sustained from the prophase to the metaphase, within the nucleus. Subsequent entry into the anaphase critically relies on the sudden destruction of the Cdk1/cyclin B activity. ${ }^{5,6}$ Accordingly, the activity of Cdk1 is regulated in a spatiotemporary pattern at several levels, namely (1) at the level of transcription of cyclin B1 and (to a lower extent on that of Cdk1); (2) at the level of regulatory Cdk1 phosphorylations; (3) at the level of the subcellular distribution of cyclin B1; and (4) at the level of the regulated degradation of cyclin B.

The transcription of Cdk1 is rather stable throughout the cell cycle, although it is modulated in pathological conditions. For instance, p53 negatively regulates Cdk1 transcription ${ }^{7}$ as well as that of cyclin $\mathrm{B}^{8}{ }^{8}$ The cyclin B gene is transcribed and its mRNA is stabilized from the end of the S-phase. The phosphorylation of Cdk1 on $\mathrm{Thr}^{14}$ (mainly by Myt1 kinase) and Tyr ${ }^{15}$ (mainly by Wee1 kinase) inhibits its activity during the $\mathrm{G}_{2}$-phase of the cell cycle, presumably through a direct effect on the phosphotransfer activity, while de-phosphorylation of Cdk1 on $\mathrm{Thr}^{14}$ and $\mathrm{Tyr}^{15}$ by the phosphatase Cdc25C de-inhibits Cdk1 during early mitosis. The regulation of Cdc25 phosphatase activity by Cdk1 itself, as well as by other phosphatases and kinases, is complex (Figure 1). The phosphorylation of $\mathrm{Thr}^{161}$ by CAC (Cdk activating kinase, a heterodimer of cyclin $\mathrm{H}$ and Cdk7), is strictly required for Cdk1 to be active. The Cdk1 inhibitor p21 $1^{\text {Cip } 1 / \text { Waf1 }}$ directly inhibits Cdk1 activity. Cyclin B1, the obligate allosteric activator of Cdk1, changes its subcellular localization from the cytosol to the nucleus, early during mitosis. The equilibrium between nuclear import and export of cyclin B1 (as well as that of Cdc25C, required for activation of Cdk1) is influenced by its phosphorylation status. ${ }^{5,6}$ At the end of the metaphase, a specialized device, the anaphase promoting complex (APC) must destroy cyclin B to allow mitosis to proceed. The APC, a polyprotein complex activated by Cdc20 recruits cyclin B, causes its ubiquitination, and thus targets it for degradation by the $26 \mathrm{~S}$ proteasome. ${ }^{9}$

The Cdk1/cyclin B heterodimer induces mitosis by phosphorylating and activating enzymes regulating chro- 


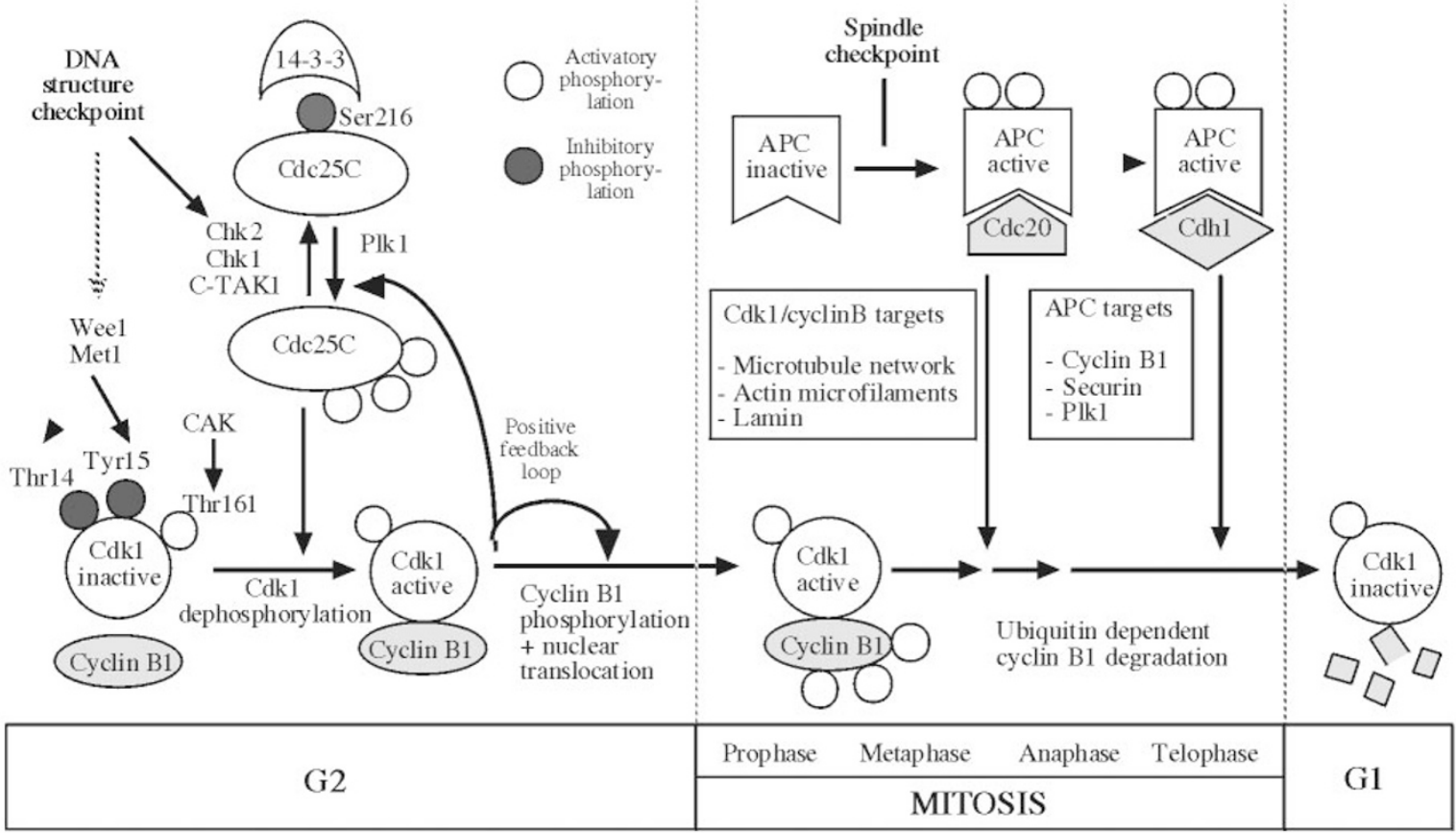

Figure 1 Regulation of Cdk1 during normal mitosis. To allow cells to progress from the G2 to the M phase, Cdk1 has to be active, meaning that it has to bear an activating phosphorylation on $\mathrm{Thr}^{161}$ by CAK, that the inhibitory phosphorylation (on $\mathrm{Thr}^{14}$ and $\mathrm{Tyr}^{15}$ ) has been removed by active Cdc25C phosphatase, and that Cdk1 associates with cyclin B and translocates to the nucleus. In the nucleus, the active Cdk1/Cyclin B complex then phosphorylates mitotic substrate proteins. During the anaphase the APC becomes activated and targets Cdk1 for degradation. Note that two cell cycle checkpoints indirectly affect the activity of Cdk1. The DNA structure checkpoint activates checkpoint kinases (such as Chk1 and Chk2), which phosphorylate Cdc25C on Ser ${ }^{216}$, thereby causing it inactivation (and failure to activate Cdk1). Activation of the spindle checkpoint delays maturation of the APC (and thus prevents cyclin B degradation)

matin condensation, nuclear membrane breakdown, mitosis-specific microtubule reorganization, and the actin cytoskeletion allowing for mitotic rounding up of the cell. ${ }^{5,6}$ It is important to note that the mitotic and apoptosis rounding up of the cell and dissolution of the nuclear envelope are fundamentally different. Thus, the mitotic dismantling of the envelope is catalyzed by kinases (and in part by Cdk1/cyclin B) which phosphorylate lamins, thereby causing their reversible depolymerization. In contrast, apoptosis involves the irreversible proteolytic cleavage of lamin $B$ by caspase-6., 3 .10

The perfect regulation of the spatiotemporal pattern of Cdk1/cyclin B activity is pivotal for the normal cell cycle and is subject to multiple control steps. Thus, the so-called 'DNA structure checkpoints' (which are activated by incomplete DNA replication or by DNA damage such as strand breaks) will stimulate Wee1/Myt1 as well as so called check point kinases (Chk1, Chk2, which inactivate Cdc25C) to prevent Cdk1 activation and entry into mitosis. Similarly, the APC can be inhibited during the 'spindle assembly checkpoint', thus preventing the degradation of Cdk1 (and that of many other substrates) and nuclear division $^{5,6,11}$ (Figure 1).

\section{Cdk1 as a target for apoptosis induction?}

Most if not all perturbations of cellular physiology can lead to apoptosis as a default pathway, ${ }^{12}$ and this apparently also applies to the induction of cell death by inhibition of Cdk1.
Using a temperature sensitive Cdk1 mutant cell line, it was shown that inactivation of Cdk1 increases the level of apoptosis induced by the topoisomerase II inhibitors mitoxantrone and teniposide. ${ }^{13}$ Similarly, down-regulation of Cdk1 in a cell line in which endogenous Cdk1 gene expression depends on the presence of an inducer in the culture medium, results in extensive DNA replication and apoptosis. ${ }^{14}$ Nonethless, there are little data suggesting that pharmacological inhibition of Cdk1 will cause apoptosis in addition to arresting the cell cycle during the G2 phase. Flavopiridol, an inhibitor of Cdk1 (and other cyclin dependent kinases) causes apoptosis in a variety of different tumor cells, including in pre-clinical mouse models ${ }^{15}$ and in clinical trials. ${ }^{16}$ Nevertheless, it appears probable that flavopiridol induces apoptosis by curtailing the activity of other kinases than Cdk1, for instance that of Cdk9, which is required for transcription. ${ }^{16}$

How can inhibition of Cdk1 lead to apoptosis? One interesting Cdk1 target is survivin, which is phosphorylated on $\mathrm{Thr}^{34} .^{17}$ Loss of phosphorylation on this residue, as a result of a genetic manipulation of survivin, can result in the dissociation of a survivin-caspase- 9 complex normally anchored on the mitotic midbody, thereby causing caspase-9-mediated apoptosis of cells traversing mitosis. ${ }^{17}$ It has also been speculated that Cdk-1 mediated phosphorylation of $\mathrm{Bcl}-2$ might be cytoprotective, at least in a model of hypericin-mediated photodynamic therapy. ${ }^{18}$ Whether the absence of phosphorylation of survivin and/or Bcl-2 truly explains the pro-apoptotic effect of Cdk1 inhibition, however, remains an ongoing conundrum, and it is formally 
possible that phosphorylation of $\mathrm{Bcl}-2$ constitutes a marker of mitosis, without any major relevance to the regulation of apoptosis.

\section{Cdk1 as a pro-apoptotic mediator}

An increase in Cdk1 activity has been found in numerous apoptotic conditions, and inhibition of the Cdk1/cyclin B complex by a dominant-negative (DN) Cdk1 mutant, antisense constructs, or chemical inhibitors have suggested that this increase in activity may be indeed important for cell killing (Table 1). In Jurkat cells, crosslinking of CD95/Fas/Apo1 causes a rapid activation of Cdk1 due to the caspase-3 mediated cleavage of Wee1 (and consequent de-phosphorylation of Cdk1 on $\left.\mathrm{Tyr}^{15}\right),{ }^{19}$ suggesting that the activation of Cdk1 observed in cell death in some cases is a consequence rather than a mechanism of apoptosis. It may also be criticized that Cdk1 inhibition will cause a G2 arrest and thus prevent apoptosis in a indirect fashion related to the cell cycle arrest. Nonetheless, several authors have suggested that $\mathrm{Cdk} 1 \mathrm{can}$ act as a pro-apoptotic mediator, as will be discussed below.

From a clinical point of view, perhaps the most interesting observation concerns Cdk1 activation by microtubule inhibitors such as paclitaxel (Taxol). Taxol has been found to increase the activity of Cdk1 in several breast cancer cell lines, presumably as an indirect consequence of

Table 1 Models of apoptosis induction involving Cdk1

\begin{tabular}{llc}
\hline Model & Observation & Reference \\
\hline HeLa cells treated with & DN Cdk1 mutant inhibits & 63 \\
staurosporine or TNF- $\alpha$ & $\begin{array}{l}\text { apoptosis } \\
\text { apos }\end{array}$
\end{tabular}

Crosslinking of CD95 in Activation of Cdk1 activity Jurkat cells DN-Cdk1 or Wee 1 inhibit apoptosis

$\gamma$-Irradiation of hematopoietic cells

Accumulation of cyclin B1 Cyclin B1 anti-sense oligo inhibits death

Activation of $\mathrm{T}$ cell hybridoma

Increased kinase activity of

Cdk1 on $\mathrm{H} 1$

Cyclin B anti-sense oligonucleotide inhibits cell death

Taxol on MCF-7 breast cancer cells

Increased Cdk1 activity Oloumycin (which inhibits Cdk1) inhibits apoptosis

Taxol on MDA-MB-435 breast cancer cells

Cerebellar granule neurons subjected to $\mathrm{KC1}$ deprivation

Increased Cdk1 activity TPA inhibits Cdk1 and apoptosis

Increased Cdk1 expression and activity DN-Cdk1 inhibits apoptosis

Increased cyclin B and

HIV-1-Env/CD4 mediated fusion of HeLa cells

HIV-1 infection of CD4 ${ }^{+}$ lymphoblasts its effects on microtubuli and the cell cycle. Chemical inhibition of Cdk1 or transfection with DN-Cdk1 blocks taxol-induced cell death ${ }^{20,21}$ (Figure 2). In this system, 12O-eteradecanaoylphorbol-13-acetate (TPA), a protein kinase $\mathrm{C}$ activator and tumor promoter, can prevent the taxolmediated Cdk1 activation without affecting the taxolinduced tubulin polymerization. ${ }^{21}$ Moreover, transfectionenforced overexpression of $\mathrm{p} 185^{\mathrm{ErbB} 2}$ protein, a plasma membrane-anchored receptor tyrosine kinase, blocks Cdk1 activation by at least two different mechanisms. First, ErbB2 causes the upregulation of $\mathrm{p} 21^{\text {Waf1/Cip1, which }}$ interacts with and inhibits Cdk1. ${ }^{21}$ The absence of p21 also sensitizes HCT116 colon carcinoma cells to the induction of apoptosis by taxol and vincristine, correlating with a prolonged Cdk1 activity and the occurrence of endoreduplication. $^{22}$ As a second mechanism of Cdk1 inhibition, ErbB2 can directly phosphorylate Cdk1 on Tyr ${ }^{15}$ (the site also targeted by Wee1); thereby causing its inactivation. ${ }^{23}$ This is a clinically important pathway of taxol resistance because ErbB2-positive mammary cancers are relatively resistant to taxol. As shown in a phase II clinical trial, such cancers become responsive to taxol in vivo when taxol is combined with Herceptin (Trastuzumab), a humanized monoclonal anti-ErbB2 antibody. ${ }^{24}$

In HL60 myelomonocytic leukemia cells, the taxolinduced Cdk1 activation is not affected by $\mathrm{Bcl}-2$ nor is it inhibited by the pan-caspase inhibitor Z-VAD.fmk, although $\mathrm{Bcl}-2$ (but not Z-VAD.fmk) does prevent the mitochondrial release of cytochrome $c{ }^{25}$ This places Cdk1 upstream of the $\mathrm{Bcl}-2$-regulated mitochondrial changes that define apoptosis. ${ }^{12,26}$ Intriguingly, two observations suggest that Cdk1 can induce mitochondrial membrane permeabilization by acting on proteins from the $\mathrm{Bcl}-2$ family. First, Cdk1 can phosphorylate the pro-apoptotic Bcl-2 protein family member Bad on Ser ${ }^{128}$, thereby causing a loss of interaction between Bad and cytosolic 14-3-3 proteins. ${ }^{27}$ As a result, Bad can translocate to mitochondria, where it antagonizes with $\mathrm{Bcl}-2$-like proteins and/or activates Baxlike proteins ${ }^{28}$ and causes mitochondrial membrane permeabilization and consequent cell death (Figure 2). Thus, at difference with other anti-apoptotic Bad kinases which phosphorylate $\mathrm{Ser}^{136}$ (Akt/PKB, PAK1, p70 ${ }^{\mathrm{S6k}}$ ) or Ser $^{112}$ (Rsk, PKA, PAK1), thus favoring the interaction between Bad and 14-3-3, Cdk1 is a pro-apoptotic Bad kinase. Indeed, the Ser ${ }^{128}$ phosphorylation of Bad inhibits the interaction of $\mathrm{Ser}^{136}$-phosphorylated Bad with 14-3-3 proteins, indicating that Cdk1 can interfere with survival signaling mediated by Akt/PKB, PAK1 and $p 70^{\text {s6k.27 }}$ In addition, $\mathrm{Cdk} 1$ may phosphorylate and inactivate $\mathrm{Bcl}-2$ on Ser70 and Ser87, that is within a proline-rich loop associated with autorepression of its anti-apoptotic activity. ${ }^{29}$ However, several groups failed to demonstrate direct $\mathrm{Bcl}-2$ phosphorylation by $\mathrm{Cdk} 1$ in vitro, ${ }^{18,30}$ and the functional consequences of the $\mathrm{Bcl}-2 \mathrm{Ser}^{70}$ phosphorylation are controversial. ${ }^{18,31}$

Unscheduled expression and activation of Cdk1/cyclin B has been seen in neurons undergoing degeneration in Alzheimer's disease, as well as in other neurodegenerative conditions, correlating with accumulation of mitotic phosphoepitopes. ${ }^{32}$ This change may be attributed to an 


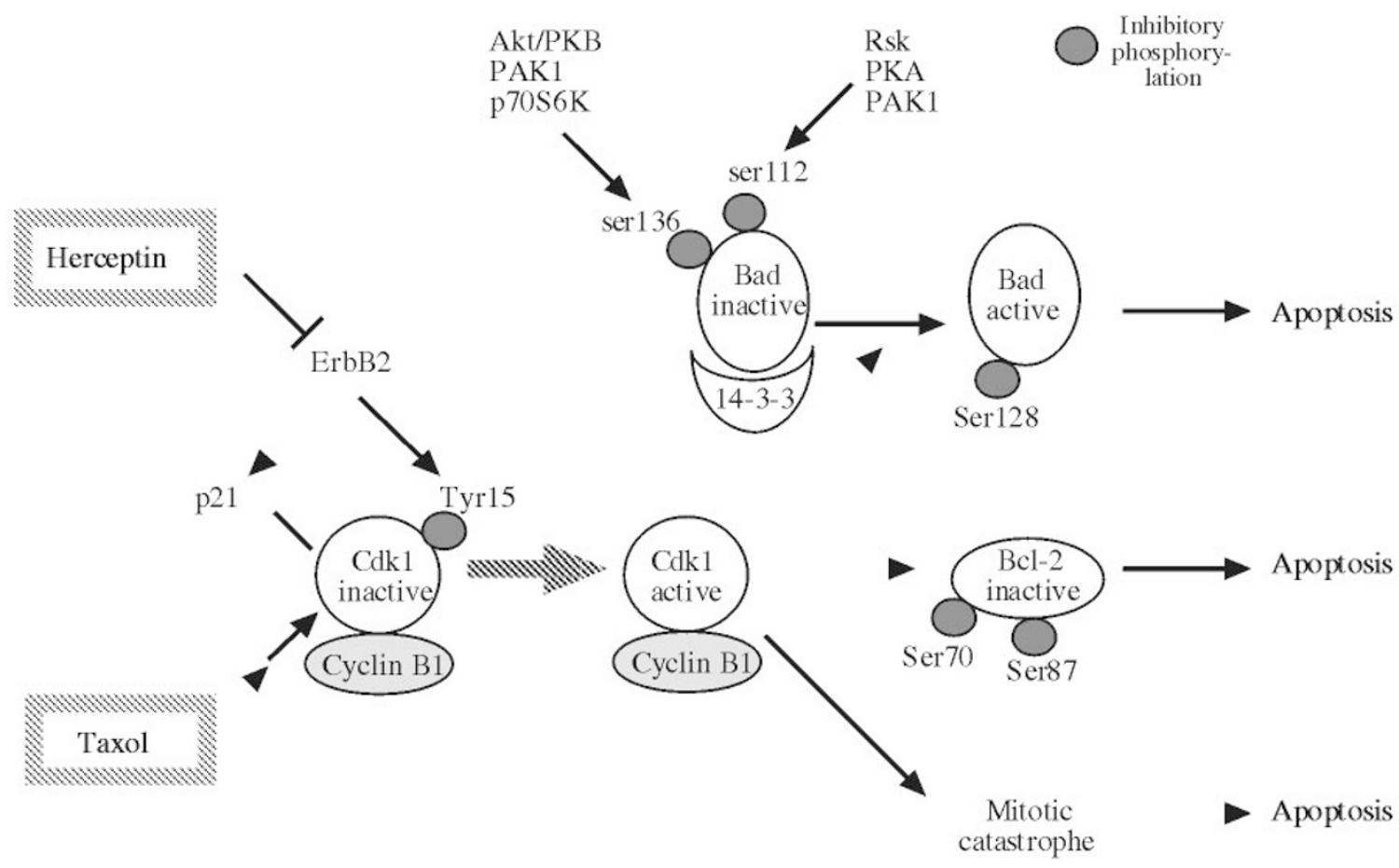

Figure 2 Involvement of Cdk1 in apoptosis. In breast cancer cells expressing ErbB2, the simultaneous application of Taxol (paclitaxel, which indirectly activates Cdk1) and Herceptin (a monoclonal ErbB2-inhibitory antibody) synergize to induce apoptosis, presumably because Herceptin relieves an ErbB2-mediated block of Cdk1. Cdk1 can induce cell death by triggering premature entry into mitosis and consequent mitotic catastrophe, followed by apoptosis. In addition, Cdk1 can phosphorylate the pro-apoptotic protein Bad, causes its removal from its site of action, the mitochondrion. Alternatively, Cdk1 can phosphorylate (and inactivate?) the anti-apoptotic protein $\mathrm{Bcl}-2$

increase in Cdc25B tyrosine phosphatase activity. ${ }^{33}$ However, thus far no evidence has been published, to our knowledge, that inhibition of Cdk1/cyclin B can protect against neurodegeneration.

\section{Cdk1 in mitotic catastrophe}

Mitotic catastrophe is the form of cell death that results from aberrant mitosis, leading to the formation of large non-viable cells with several micronuclei containing uncondensed chromosomes. Although apoptosis may be a consequence of mitotic catastrophe, it would be a misconception to assume that apoptosis would be required for the lethal effect of mitotic catastrophe. ${ }^{34}$ Although the expression of anti-apoptotic proteins such as $\mathrm{Bcl}-2$ or MDA can prevent apoptosis occurring after mitotic catastrophe, it does not improve clonogenic survival. ${ }^{34,35}$ Mitotic catastrophe can result from deficient mitotic checkpoints in tumor cells, anti-microtubular drugs, and premature mitosis. All these conditions may involve the unscheduled activation of Cdk1. For instance, the fusion of mitotic cells with interphase cells in S or G2 can result in mitotic catastrophe, presumably due to the premature induction of mitosis before the completion of $\mathrm{S}$ or $\mathrm{G} 2{ }^{36}$ This premature induction obviously involves the 'mitosis-promoting factor', Cdk1/cyclin B1. Accordingly, ectopic overexpression of cyclin B plus Cdk1 can result in premature chromatin condensation and mitotic catastrophe. ${ }^{37,38}$ Similarly, in cells expressing p21 under the control of an inducible promoter, the sudden reduction of p21 expression (which de-represses
Cdk1) can lead to mitotic catastrophe after prolonged growth arrest. $^{39}$

Mitotic catastrophe may be a clinically important modality of cell death, because DNA damage, for instance induced by $\gamma$-irradiation, which normally activates the DNA damage checkpoint (Figure 1,2), fails to do so in cancer cells lacking sensors of DNA damage (e.g. ATM, ATR), adaptors (e.g. BRCA1) or effector kinases (e.g. Chk1, Chk2) required for cell cycle arrest. ${ }^{11}$ This may explain why cancer cells are particularly sensitive to the induction of mitotic catastrophe. Moreover, chemical inhibitors of check point kinases can sensitize tumor cells to the induction of mitotic catastrophe (and subsequent apoptosis). ${ }^{40-43}$

\section{Cdk1 in the cytopathogenicity of human immunodeficiency virus-1 (HIV-1)}

Peripheral CD4 and CD8 cells from HIV-1-infected donors overexpress cyclin $\mathrm{B}$ and frequently contain two nucleolar organizer regions (NOR), which is a marker of the G2 phase. These alterations return to normal after successful antiretroviral therapy. ${ }^{44,45}$ The increased expression of cyclin B has been correlated with an enhanced half-life of the cyclin B protein and is associated with a decreased level of cyclin B ubiquitination. ${ }^{45}$

In vitro, $\mathrm{CD}^{+}{ }^{+} \mathrm{T}$ cells exposed to cells expressing the HIV-1 envelope (Env) gene can undergo cell death while arresting in the G2/M-phase without any significant formation of syncytia. Such cells manifest the inhibitory 
hyperphosphorylation of Cdk1, as well as an increase in cyclin B. ${ }^{46}$ Coculture of HeLa cells transfected with Env with HeLa cells transfected with CD4 (and spontaneously expressing CXCR4) results in the formation of multinuclear giant cells, which undergo apoptosis after a latency period of 24-48 h. ${ }^{47}$ In most cases, apoptosis occurs without features of mitotic catastrophe. ${ }^{48}$ Formation of HeLa Env/ CD4 syncytia is accompanied by a progressive accumulation of cyclin $\mathrm{B}$ in the cytoplasm. ${ }^{49}$ Enzymatic assays performed on syncytium-derived cyclin B-dependent kinase-1 (Cdk1) indeed reveal a transient increase in the enzymatic activity of Cdk1, peaking around $12 \mathrm{~h}$ after the initial fusion event. ${ }^{49}$ Thereafter, cyclin B translocates to the nucleus, a phenomenon which occurs at the same time or shortly before the dissolution of the nuclear envelope. This process is accompanied by depolymerization of lamins and thus resembles the first step of the mitotic prophase. The dissolution of the nuclear envelope (which also can be induced by microinjection of active cyclin B/Cdk1 complexes) ${ }^{49}$ culminates into nuclear fusion (also called 'karyogamy'), as indicated by a loss of nuclear contours within the heterokaryon. ${ }^{50}$ At this stage, mTOR translocates to the nucleus and phosphorylates p53, causing its transcriptional activation. ${ }^{51,52}$ Thus, a signal transducing cascade involving transcriptional activation of p53 by mammalian target of rapamycin (mTOR), p53-mediated upregulation of pro-apoptotic Bax protein, and Baxmediated permeabilization of mitochondrial membranes participates in syncytial cell death, both in HeLa Env/CD4 syncytia and in lymphocytes infected by HIV-1. ${ }^{51,53}$ How the Cdk1/cyclin B complex is activated in Env-induced syncytia or in HIV-1 infected patients is an ongoing conundrum. Nonetheless, it is clear that inhibition of Cdk1, either by transfection with $\mathrm{DN}-\mathrm{Cdk} 1^{49}$ or by treatment with the pharmacological Cdk1 inhibitor roscovitine (Figure 3) can prevent the apoptosis of syncytia elicited by the interaction between HIV-1 Env and CD4.

Vpr, another pro-apoptotic protein encoded by HIV-1, has been shown to arrest cell cycle in G2 due to an inhibition of Cdk1. Thus, the transfection-enforced expression of $\mathrm{Vpr}$ reportedly causes $\mathrm{Cdk} 1$ to remain in the phosphorylated, inactive state,$^{54}$ an observation that, however, has not been confirmed by other authors. ${ }^{55}$ Coexpression of a constitutively active mutant Cdk1 molecule with $\mathrm{Vpr}$ relieved the G2 arrest, ${ }^{54}$ indicating that Vpr might induce apoptosis via its capacity to inhibit Cdk1 and to arrest the cell cycle in the G2 phase. However, a number of mutants of $\mathrm{Vpr}$ (e.g. truncation at C81) have been described to induce apoptosis without causing a G2 arrest, $^{56,57}$ indicating that the two functions can be uncoupled. ${ }^{58}$ Accordingly, the addition of $\mathrm{Vpr}$ has no peculiar effect on syncytial apoptosis (as would be expected if it aggravated the cell cycle perturbation). ${ }^{59}$ Rather, current observations are in line with the hypothesis that Vpr induces apoptosis through a mitochondrial pathway not related to $\mathrm{Cdk1} .^{59,60}$ It will be interesting to follow the cell cycle characteristics of peripheral T cells from HIV1-infected long-term non-progressors lacking the apoptogenic domain of $\mathrm{Vpr}$, either due to a point mutation $(\mathrm{R} 77 \mathrm{Q})^{61,62}$ or due to stop mutations. ${ }^{57}$

\section{Conclusions}

Cdk1 appears to be a major player in the homeostatic control defining the frontier between normal cellular replication, repair after damage, mitotic catastrophe and apoptosis. Clearly, uncontrolled Cdk1 activation can lead to a premature attempt of mitosis with catastrophic consequences and subsequent
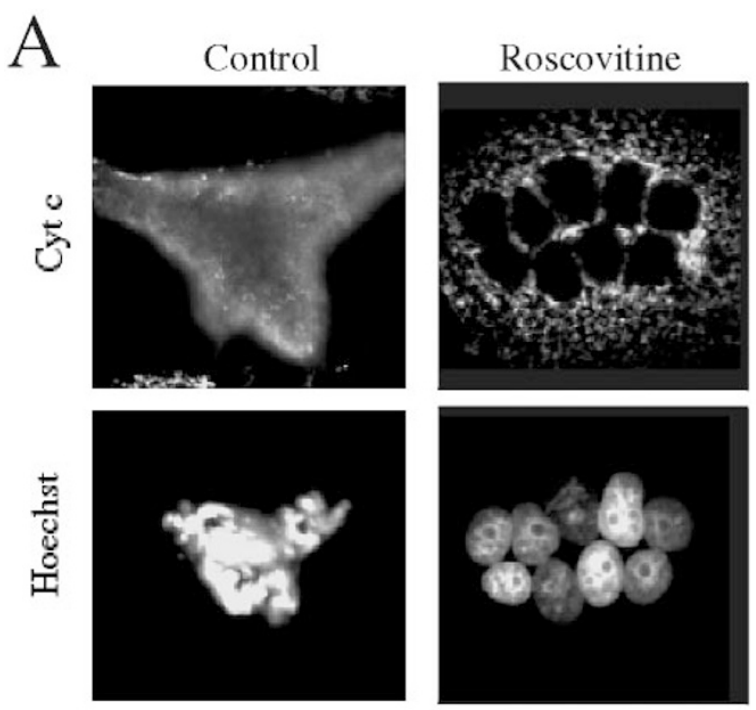

$20 \mu \mathrm{M}$
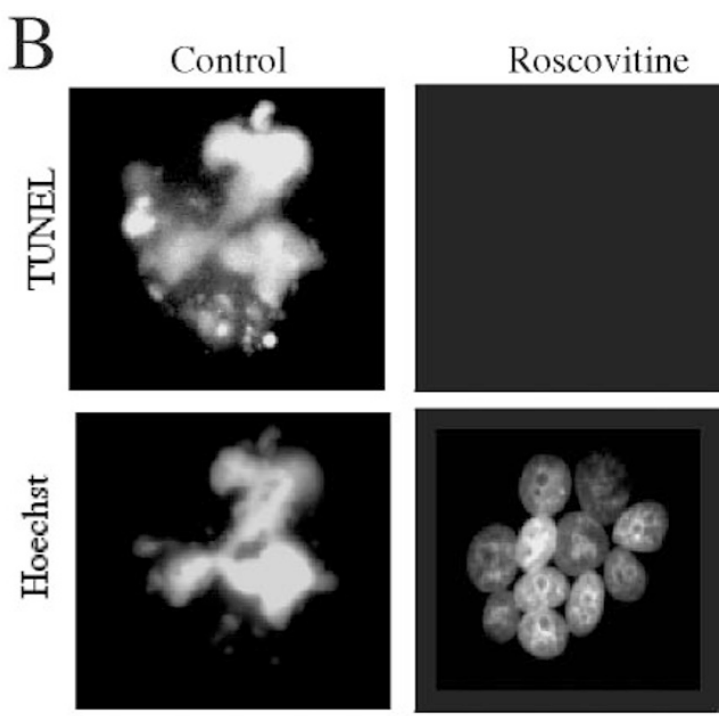

Figure 3 Cdk1-dependent apoptosis in syncytia elicited by the interaction between HIV-1 Env and CD4. HeLa cells expressing either HIV-1 Env or HIV-1 CD4 were co-cultured in the absence (control) or presence of roscovitine, a chemical Cdk1 inhibitor ( $10 \mu \mathrm{M}, 48 \mathrm{~h}$ ), followed by immunostaining for the detection of cytochrome $c(\mathbf{A})$ or TUNEL staining $(\mathbf{B})$ and counterstaining with Hoechst $33324(\mathbf{A}, \mathbf{B})$. Representative images show that roscovitine maintains cytochrome $c$ in mitochondria and prevents DNA degradation 
apoptosis. Cdk1 can also stimulate the activation of the apoptotic pathway in a direct fashion, through an action on $\mathrm{Bcl}-2$ family proteins. The abnormal activation of Cdk1 is likely to be involved in the unwarranted cell loss accompanying HIV1 infection and neurodegenerative disease. In addition, the failure of Cdk1 activation may determine the abnormal resistance of cancer cells to chemotherapy. In this context, it will be important to develop new strategies for the cell typespecific activation or inhibition of Cdk1 with the ultimate goal to correct disease-relevant imbalances in apoptosis control.

\section{Acknowledgements}

Supported by a special grant from the Ligue Nationale contre le Cancer, as well as by grants from ANRS, Sidaction, and European Commission (QLG1-CT-1999-00739) (to G Kroemer).

\section{References}

1. Shi L, Nishioka WK, Th'ng J, Bradbury EM, Litchfield DW and Greenberg AH (1994) Premature p34 $4^{\mathrm{cdc} 2}$ activation required for apoptosis. Science 263 : $1143-1145$

2. Freeman RS, Estus S and Johnson Jr EM (1994) Analysis of cell cycle-related gene expression in postmitotic neurons: selective induction of Cyclin D1 during programmed cell death. Neuron 12: 343-355

3. Oberhammer FA, Hochegger $\mathrm{K}$ and Froschl G (1994) Chromatin condensation during apoptosis is accompanied by degradation of lamin $A+B$, without enhanced activation of cdc-2 kinase. J. Cell Biol. 126: 827-837

4. Norbury C, MacFarlande M, Fearnhead H and Cohen GM (1994) CDC2 activation is not required for thymocyte apoptosis. Biochem. Biophys. Res. Comm. 202: $1400-1406$

5. Nigg EA (2001) Mitotic kinases as regulators of cell division and its checkpoints. Nat. Rev. Mol. Cell Biol. 2: 21-32

6. Smits VA and Medema RH (2001) Checking out the G2/M transition. Biochim. Biophys. Acta 1519: 1-12

7. Yun J, Chae HD, Choy HE, Chung J, Yoo HS, Han MH and Shin DY (1999) p53 negatively regulates cdc2 transcription via the CCAAT-binding NF-Y transcription factor. J. Biol. Chem. 274: 29677-29682

8. Taylor WR, DePrimo SE, Agarwal A, Agarwal ML, Schonthal AH, Katula KS and Stark GR (1999) Mechanisms of G2 arrest in response to overexpression of p53. Mol. Biol. Cell 10: 3607-3622

9. Peters JM (2002) The anaphase-promoting complex: proteolysis in mitosis and beyond. Mol. Cell. 9: 931-943

10. Ruchaud S, Korfali N, Villa P, Kottke TJ, Dingwall C, Kaufmann SH and Earnshaw WC (2002) Caspase-6 gene disruption reveals a requirement forlamin A cleavage in apoptotic chromatin condensation. EMBO J. 21: 1967-1977

11. Melo J and Toczyski $D$ (2002) A unified view of the DNA-damage checkpoint. Curr. Opin. Cell. Biol. 14: 237-245

12. Ferri KF and Kroemer GK (2001) Organelle-specific initiation of cell death pathways. Nature Cell Biol. 3: E255-E263

13. Ongkeko W, Ferguson DJP, Harris AL and Norbury C (1995) Inactivation of Cdc2 increases the level of apoptosis induced by DNA damage. J. Cell Science 108: 2897-2904

14. Itzhaki JE, Gilbert CS and Porter AC (1997) Construction by gene targeting in human cells of a 'conditional' CDC2 mutant that rereplicates its DNA. Nat. Genet 15: $258-265$

15. Patel V, Senderowicz AM, Pinto Jr D, Igishi T, Raffeld M, Quintanilla-Martinez L, Ensley JF, Sausville EA and Gutkind JS (1998) Flavopiridol, a novel cyclindependent kinase inhibitor, suppresses the growth of head and neck squamous cell carcinomas by inducing apoptosis. J. Clin. Invest. 102: 1674-1681

16. Zhai S, Senderowicz AM, Sausville EA and Figg WD (2002) Flavopiridol, a nove cyclin-dependent kinase inhibitor, in clinical development. Ann. Pharmacother. 36: $905-911$
17. O'Connor DS, Grossman D, Plescia J, Li F, Zhang H, Villa A, Tognin S, Marchisio PC and Altieri DC (2000) Regulation of apoptosis at cell division by p34cdc2 phosphorylation of survivin. Proc. Natl. Acad. Sci .USA 97: 13103-13107

18. Vantieghem A, Xu Y, Assefa Z, Piette J, Vandenheede JR, Merlevede W, De Witte PA and Agostinis P (2002) Phosphorylation of BCL-2 in G2/M phase arrested cells following photodynamic therapy with hypericin involves a CDK1mediated signal and delays the onset of apoptosis. J. Biol. Chem. in press.

19. Zhou BB, Li H, Yuan J and Kirschner MW (1998) Caspase-dependent activation of cyclin-dependent kinases during Fas- induced apoptosis in Jurkat cells. Proc. Natl. Acad. Sci. USA 95: 6785-6790

20. Shen SC, Huang TS, Jee SH and Kuo ML (1998) Taxol-induced p34cdc2 kinase activation and apoptosis inhibited by 12-0- tetradecanoylphorbol-13-acetate in human breast MCF-7 carcinoma cells. Cell Growth Differ. 9: 23-29

21. Yu D, Jing T, Liu B, Yao J, Tan M, McDonnell TJ and Hung MC (1998). Overexpression of ErbB2 blocks Taxol-induced apoptosis by upregulation of p21Cip1, which inhibits p34Cdc2 kinase. Mol. Cell 2: 581-591

22. Stewart ZA, Mays D and Pietenpol JA (1999) Defective G1-S cell cycle checkpoint function sensitizes cells to microtubule inhibitor-induced apoptosis. Cancer Res., 59: 3831-3837

23. Tan M, Jing T, Lan KH, Neal CL, Li P, Lee S, Fang D, Nagata Y, Liu J, Arlinghaus $R$, Hung MC and Yu D (2002) Phosphorylation on tyrosine-15 of p34(Cdc2) by ErbB2 inhibits p34(Cdc2) activation and is involved in resistance to taxol-induced apoptosis. Mol. Cell 9: 993-1004

24. Slamon DJ, Leyland-Jones B, Shak S, Fuchs $H$, Paton V, Bajamonde A, Fleming $T$, Eiermann W, Wolter J, Pegram M, Baselga J and Norton L (2001) Use of chemotherapy plus a monoclonal antibody against HER2 for metastatic breast cancer that overexpresses HER2. N. Engl. J. Med. 344: 783-792

25. Ibrado AM, Kim CN and Bhalla K (1998). Temporal relationship of CDK1 activation and mitotic arrest to cytosolic accumulation of cytochrome $\mathrm{C}$ and caspase-3 activity during Taxol-induced apoptosis of human AML HL-60 cells. Leukemia 12: 1930-1936

26. Kroemer G and Reed JC (2000) Mitochondrial control of cell death. Nat. Med. 6: $513-519$

27. Konishi Y, Lehtinen M, Donovan N and Bonni A (2002) Cdc2 phosphorylation of BAD links the cell cycle to the cell death machinery. Mol. Cell. 9: 1005-1016

28. Debatin K-M, Poncet D and Kroemer G (2002) Chemotherapy: Targeting the mitochondrial pathway. Oncogene in press

29. Pathan N, Aime-Sempe C, Kitada S, Haldar S and Reed JC (2001) Microtubuletargeting drugs induce Bcl-2 phosphorylation and association with Pin1. Neoplasia 3: $70-79$

30. Scatena CD, Stewart ZA, Mays D, Tang LJ, Keefer CJ, Leach SD and Pietenpol JA (1998) Mitotic phosphorylation of Bcl-2 during normal cell cycle progression and Taxol-induced growth arrest. J. Biol. Chem. 273: 30777-30784

31. Yamamoto K, Ichijo H and Korsmeyer SJ (1999) BCL-2 is phosphorylated and inactivated by an ASK1/Jun N-terminal protein kinase pathway normally activated at G(2)/M. Mol. Cell. Biol. 19: 8469-8478

32. Vincent I, Jicha G, Rosado M and Dickson DW (1997) Aberrant expression of mitotic cdc2/cyclin B1 kinase in degenerating neurons of Alzheimer's disease brain. J. Neurosci. 17: 3588-3598

33. Vincent I, Bu B, Hudson K, Husseman J, Nochlin D and Jin L (2001) Constitutive $\mathrm{Cdc} 25 \mathrm{~B}$ tyrosine phosphatase activity in adult brain neurons with $\mathrm{M}$ phase-type alterations in Alzheimer's disease. Neuroscience 105: 639-650

34. Roninson IB, Broude EV and Chang B-D (2002) If not apoptosis, then what? Treatment-induced senescence and mitotic catastrophe in tumor cells. Drug Resistance Updates 4: 303-313

35. Lock RB and Stribinskiene L (1996) Dual modes of death induced by etoposide in human epithelial tumor cells allow Bcl-2 to inhibit apoptosis without affecting clonogenic survival. Cancer Res. 56: 4006-4012

36. Mackey MA, Zhang XF, Hunt CR, Sullivan SJ, Blum J, Laszlo A and Roti Roti JL (1996) Uncoupling of M-phase kinase activation from the completion of S-phase by heat shock. Cancer Res. 56: 1770-1774

37. Heald R, McLoughlin M and McKeon F (1993) Human wee1 maintains mitotic timing by protecting the nucleus from cytoplasmically activated $C d c 2$ kinase. Cell 74: $463-474$

38. Jin P, Hardy S and Morgan DO (1998) Nuclear localization of cyclin B1 controls mitotic entry after DNA damage. J. Cell. Biol. 141: 875-885 
39. Chang BD, Broude EV, Fang J, Kalinichenko TV, Abdryashitov R, Poole JC and Roninson IB (2000) p21Waf1/Cip1/Sdi1-induced growth arrest is associated with depletion of mitosis-control proteins and leads to abnormal mitosis and endoreduplication in recovering cells. Oncogene 19: 2165-2170

40. Graves PR, Yu L, Schwarz JK, Gales J, Sausville EA, O'Connor PM and Piwnica-Worms $H(2000)$ The Chk1 protein kinase and the Cdc25C regulatory pathways are targets of the anticancer agent UCN-01. J. Biol. Chem. 275: $5600-5605$

41. Curman D, Cinel B, Williams DE, Rundle N, Block WD, Goodarzi AA, Hutchins JR, Clarke PR, Zhou BB, Lees-Miller SP, Andersen RJ and Roberge M (2001) Inhibition of the G2 DNA damage checkpoint and of protein kinases Chk1 and Chk2 by the marine sponge alkaloid debromohymenialdisine. J. Biol. Chem. 276: $17914-17919$

42. Hu B, Zhou XY, Wang $X$, Zeng ZC, lliakis G and Wang $Y$ (2001) The radioresistance to killing of $A 1-5$ cells derives from activation of the Chk1 pathway. J. Biol. Chem. 276: 17693-17698

43. Hirose Y, Berger MS and Pieper RO (2001) Abrogation of the Chk1-mediated $\mathrm{G}(2)$ checkpoint pathway potentiates temozolomide-induced toxicity in a p53independent manner in human glioblastoma cells. Cancer Res. 61: 5843-5849

44. Piedimonte G, Corsi D, Paiardini M, Cannavo G, lentile R, Picerno I, Montroni M, Silvestri G and Magnani M (1999) Unscheduled cyclin B expression and p34 cdc2 activation in T lymphocytes from HIV-infected patients. Aids 13: 1159-1164

45. Paiardini M, Galati D, Cervasi B, Cannavo G, Galluzzi L, Montroni M, Guetard D, Magnani M, Piedimonte G and Silvestri G (2001) Exogenous interleukin-2 administration corrects the cell cycle perturbation of lymphocytes from human immunodeficiency virus-infected individuals. J. Virol. 75: 10843-10855

46. Kolesnitchenko V, WahI LM, Tian H, Sunila I, Tani Y, Hartmann D-P, Cossman J, Raffeld M, Orenstein J, Samelson E and Cohen DI (1995) Human immunodeficiency virus 1 envelope-initiated G2-phase programmed cell death. Proc. Natl. Acad. Sci. USA 92: 11889-11893

47. Ferri KF, Jacotot E, Blanco J, Esté JA, Zamzami A, Susin SA, Brothers G, Reed $\mathrm{JC}$, Penninger JM and Kroemer G (2000) Apoptosis control in syncytia induced by the HIV-1-envelope glycoprotein complex. Role of mitochondria and caspases. J. Exp. Med. 192: 1081-1092

48. Castedo M and Kroemer G (2002) The beauty of death. Trends Cell Biol. in press

49. Castedo M, Roumier T, Blanco J, Ferri KF, Barretina J, Andreau K, Perfettini J-L, Armendola A, Nardacci R, LeDucP, IngberDE, Este JA, Modjtahedi N, Piacentini $M$ and Kroemer G (2002) Sequential involvement of Cdk1, mTOR and p53 in apoptosis induced by the human immunodeficiency virus- 1 envelope. EMBO J. 15: $4070-4080$

50. Ferri KF, Jacotot E, Geuskens M and Kroemer G (2000) Apoptosis and karyogamy in syncytia induced by HIV-1-ENV/CD4 interaction. Cell Death Differ. 7: $1137-1139$

51. Castedo M, Ferri KF, Blanco J, Roumier T, Larochette N, Barretina J, Amendola A, Nardacci R, Metivier D, Este JA, Piacentini M and Kroemer G (2001) Human immunodeficiency virus 1 envelope glycoprotein complex-induced apoptosis involves mammalian target of rapamycin/FKBP12-rapamycin-associated protein-mediated p53 phosphorylation. J. Exp. Med. 194: 1097-1110

52. Castedo M, Ferri KF and Kroemer G (2002). Mammalian target of rapamycin (mTOR): pro- and anti-apoptotic. Cell Death Differ. 9: 99-100
53. Genini D, Sheeter D, Rought S, Zaunders JJ, Susin SA, Kroemer G, Richman DD, Carson DA, Corbeil J and Leoni, LM (2001) HIV induced lymphocyte apoptosis by a 53 -initiated, mitochondrion-mediated mechanism. FASEB J. 15: $5-6$

54. He J, Choe S, Walker R, Di Marzio P, Morgan DO and Landau NR (1995) Human immunodeficiency virus type 1 viral protein $R(V p r)$ arrests cells in the $G 2$ phase of the cell cycle by inhibiting p34cdc2 activity. J. Virol. 69: 6705-6711

55. Stewart SA, Poon B, Jowett JB and Chen IS (1997) Human immunodeficiency virus type 1 vpr induces apoptosis following cell cycle arrest. J. Virol. 71:55795592

56. Nishizawa M, Kamata M, Katsumata R and Aida Y (2000) A carboxy-terminally truncated form of the human immunodeficiency virus type $1 \mathrm{Vpr}$ protein induces apoptosis via G1 cell cycle arrest. J. Virol. 74: 6058-6067

57. Somasundaran M, Sharkey M, Brichacek B, Luzuriaga K, Emerman M, Sullivan JL and Stevenson M (2002) Evidence for a cytopathogenicity determinant in HIV1 Vpr. Proc. Natl. Acad. Sci. USA 99: 9503-9508

58. Jacotot E, Ravagnan L, Loeffler M, Ferri KF, Vieira HLA, Zamzami N, Costantini $P$, Druillennec S, Hoebeke J, Brian JP, Irinopoulos T, Daugas E, Susin SA, Cointe D, Xie ZH, Reed JC, Roques BP and Kroemer G (2000) The HIV-1 viral protein R induces apoptosis via a direct effect on the mitochondrial permeability transition pore. J. Exp. Med. 191: 33-45

59. Roumier T, Vieira HLA, Castedo M, Ferri KF, Boya P, Andreau K, Druillennec S, Joza N, Penninger JM, Roques B and Kroemer G (2002) The C-terminal moiety of HIV-1 Vprinduces cell death via a caspase-independent mitochondrial pathway. Cell Death Differ. in press

60. Jacotot E, Ferri KF, El Hamel C, Brenner C, Druillennec S, Hoebeke J, Rustin P, Métivier D, Lenoir C, Geuskens M, Vieira HLA, Loeffler M, Belzacq A-S, Briand J-P, Zamzami N, Edelman L, Xie ZH, Reed JC, Roques BP and Kroemer G (2001) Control of mitochondrial membrane permeabilization by adenine nucleotide translocator interacting with HIV-1 Vpr and Bcl-2. J. Exp. Med. 193: 509-520

61. Wang B, Ge YC, Palasnthiran P, Xiang SH, Ziegler J, Dwyer DE, Randle C, Dowton D, Cunningham A and Saksena NK (1996) Gene defects clustered at the C-terminus of the vprgene of HIV-1 in long-term nonprogressing mother and child pair: in vivo evolution of vpr quasispecies in blood and plasma. Virology 223: $224-232$

62. Zhang L, Huang Y, Yuan H, Tuttleton S and Ho DD (1997) Genetic characterization of vif, vpr and vpu sequences from long-term survivors of human immunodeficiency virus type 1 infection. Virology 228: 340-349

63. Meikrantz W and Schlegel R (1996). Suppression of apoptosis by dominant negative mutants of cyclin-dependent protein kinases. J. Biol. Chem. 271: 10205-10209

64. Yao SL, McKenna KA, Sharkis SJ and Bedi A (1996) Requirement of p34cdc2 kinase for apoptosis mediated by the Fas/APO-1 receptor and interleukin 1 betaconverting enzyme-related proteases. Cancer Res. 56: 4551-4555

65. Porter LA, Singh G and Lee JM (2000) Abundance of cyclin B1 regulates gammaradiation-induced apoptosis. Blood 95: 2645-2650

66. Fotedar R, Flatt J, Gupta S, Margolis RL, Fitzgerald P, Messier H and Fotedar A (1995) Activation-induced T-cell death is cell cycle dependent and regulated by cyclin B. Mol. Cell. Biol, 15: 932-942 